\title{
Identification of Factors Causing Sudden Coagulation in Patients with Acute Myocardial Infarction
}

\author{
Arnaldo Pinelli*, S. Trivulzio, S. Brenna², V. Rosato ${ }^{3}$, L. Rivoltini' ${ }^{4}$ and G. Rossoni ${ }^{1}$ \\ ${ }^{1}$ Department of Medical Biotechnology and Translational Medicine, University of Milan, Italy \\ 'Laboratory of Clinical Chemistry, Ospedale Niguarda Ca' Granda, Milan, Italy \\ ${ }^{3}$ Department of Clinical Science and Community, Milan, Italy \\ ${ }^{4}$ IRCCS Foundation National Institute of Cancer, Milan, Italy
}

\begin{abstract}
Background: Coronary artery disease (CAD) evolving to acute myocardial infarction (AMI) is due to the thrombotic occlusion of coronary vessels in the presence of destabilized atheroma, rich in inflammatory cells secreting proteolytic enzymes that induce the development of thrombosis. The aim of this study was to analyse the plasma of AMI patients for the detection of proteases or factors that may cause fast coagulation.

Methods: The patients were analysed for the presence in plasma of cardiac troponin T (c-TnT) or proteases as neutrophil gelatinase-associated lipocalin (NGAL) using ELISA method and matrix metalloproteinase-9 (MMP-9) utilising flow cytometry technique and interleukin-8 (IL-8) using flow cytometry methodology.

Results: The presence of AMI was demonstrated by high levels of c-TnT; in comparison with controls the AMI patients displayed a significant increase in the values of MMP-9 and low levels of antithrombin III: these markers were negatively correlated: MMP-9 appeared to cause the coagulation activity documented by the consumption of antithrombin III. The same patients also showed high levels of NGAL, which is known to modulate MMP-9 activity and to be involved in coagulation process: patients also exhibited an increased amount of IL-8 which appears to be associated with high levels of NGAL: this cytokine seems to affect the values of NGAL which is linked to coagulation process.
\end{abstract}

Conclusion: The high levels of MMP-9, NGAL and IL-8 in AMI patients seemed to be interrelated and connected with the process leading to rapid coagulation. These markers may be measured in absence of AMI, particularly in CAD patients, as their detection may reveal a risk of sudden coronary coagulation.

Keywords: Acute Myocardial Infarction (AMI); Coronary Artery Diseases (CAD); Unstable atherosclerotic plaque; Matrix Metalloproteinase-9 (MMP-9); Neutrophil Gelatinase-Associated Lipocalin (NGAL); Interleukin-8 (IL-8)

\section{Introduction}

Coronary artery disease (CAD) evolving to acute myocardial infarction (AMI) is associated with the thrombotic occlusion of coronary vessels in the presence of atheromatous plaque [1]. The atheroma is rich in inflammatory cells secreting proteolytic enzymes that may erode the fibrous cap and facilitate its rupture (unstable plaque) [2], and induce the development of coagulation and thrombosis [3].

It can be hypothesised that these secreted proteases such as matrix metalloproteinase-9 (MMP-9) [2], gelatinases such as neutrophil gelatinase-associated lipocalin (NGAL) [4], and cytokines such as IL-8 [5] may be involved in the sudden coagulation process: their proteolytic activity may activate the development of thrombosis observed in acute myocardial infarction.

The aim of this study was to analyse the plasma of healthy subjects and AMI patients for the detection of proteases that may cause fast coagulation, in particular MMP-9, NGAL and the interleukin IL-8.

\section{Patients and Methods}

Eight randomly selected male AMI patients aged 50-65 years and eight healthy male subjects of the same age were selected in order to verify whether these markers are interrelated in priming the coagulation and thrombosis that leads to AMI. This preliminary study was approved by the Ethical Committee of Niguarda Ca' Granda Hospital Milan - Italy.
The presence of AMI was demonstrated by measuring the specific marker c-TnT [6] and the plasma levels were evaluated using a commercial kit provided by Roche (Milan, Italy) [6].

MMP-9 and IL-8 were assayed using a BenderMed System flow cytomix simplex kits given by Prodotti Gianni (Milan, Italy), which were selected as representative examples of technologies currently used for high-throughput immunoanalysis [7]. NGAL was analysed using an enzyme-linked immunosorbent assay (ELISA) [8] supplied by Bioporto Diagnostic (Verona, Italy) in accordance with the manufacturer's instructions. Plasma antithrombin III was measured using colorimetric method, based on a chromogenic substrate: S-2765:N-Z-D-ARG-GLYARG-pNA using a kit provided by Instrumentation Laboratory (Milan, Italy) [9].

\section{Statistical analysis}

The values of the various biochemical markers, in the plasma of normal subjects and AMI patients, were compared using KruskalWallis test and the significance of differences $(\mathrm{P})$ was calculated $[10,11]$.

*Corresponding author: Professor Arnaldo Pinelli, Department of Medical Biotechnology and Translational Medicine, Via Vanvitelli 32, 20129 - Milan, Italy, Tel: +39 02 50317086; Fax: +39 02 50316949; E-mail: arnaldo.pinelli@unimi.it

Received April 03, 2012; Accepted June 22, 2012; Published June 25, 2012

Citation: Pinelli A, Trivulzio S, Brenna S, Rosato V, Rivoltini L, et al. (2012) Identification of Factors Causing Sudden Coagulation in Patients with Acute Myocardial Infarction. J Clin Exp Cardiolog 3:202. doi:10.4172/2155-9880.1000202

Copyright: () 2012 Pinelli A, et al. This is an open-access article distributed unde the terms of the Creative Commons Attribution License, which permits unrestricted use, distribution, and reproduction in any medium, provided the original author and source are credited. 
The correlations between MMP-9 and antithrombin III or IL-8 and NGAL were calculated using Spearman's correlation coefficient $[10,11]$.

\section{Results}

Table 1 shows the plasma values of $\mathrm{c}$-TnT $(\mathrm{ng} / \mathrm{ml})$ observed in healthy subjects $(<0.01)$ and AMI patients $(3.20)$ with highly significant difference: $\mathrm{P}<0.001$. c-TnT is a specific marker of AMI and clearly demonstrates the presence of AMI.

Table 1 reports the plasma values of MMP-9, antithrombin III, NGAL and IL-8 expressed as median and their significance calculated with Kruskal-Wallis test.

In particular the plasma levels of MMP-9 ( $\mathrm{ng} / \mathrm{ml})$ observed in healthy subjects (29.25) and in AMI patients (32.35) exhibited significantly different values: $\mathrm{P}<0.034$. The MMP-9 detected in plasma may affect biochemical process.

The levels of antithrombin III (mg/dl) found in healthy subjects (109.50) and AMI patients (96.00) appear to be significantly different: $\mathrm{P}<0.004$.

The values of NGAL $(\mathrm{ng} / \mathrm{ml})$ detected in healthy subjects $(67.00)$ and AMI patients $(157.00)$ differ very significantly: $\mathrm{P}<0.004$. The high increase of NGAL in AMI patients suggests a role of this marker in myocardial damage.

The values of IL- $8(\mathrm{pg} / \mathrm{ml})$ observed in healthy subjects (13.82) and AMI patients (27.30) were significantly different: $\mathrm{P}<0.027$. The increase of IL-8 suggests a role of this inflammatory marker in myocardial infarction.

The Spearman correlation between MMP-9 and antithrombin III appears to be significant $(\mathrm{r}=-0.523 ; \mathrm{P}=0.05)$.

\section{Discussion}

The occurrence of AMI was demonstrated by high levels of the specific c-TnT marker [6] (Table 1). Remarkably, in the AMI patients, affected by acute coronary coagulation, were found, altered plasma values of MMP-9, antithrombin III, NGAL and IL-8. It appears to be quite important to analyse the links between these altered factors and the priming of coagulation. The AMI patients had higher MMP-9 levels than the controls. In addition, they had lower amount of antithrombin III, which is consumed by coagulation [12] and the lowering of antithrombin III during AMI or unstable angina was reported also by other authors $[12,13]$. Significant negative correlation between MMP9 and antithrombin III ( $\mathrm{r}=-0.523 ; \mathrm{P}=0.05$; Spearman correlation) suggests that the former affected the levels of the latter and promoted coagulation. The process of coagulation is activated by MMP-9, which cleaves and inactivates tissue factor inhibitor and does not cleave tissue factor and factor VIIa [14]: thus MMP-9 allows the tissue factor to interact with factor VIIa: i.e. the clot starts with MMP-9 priming

\begin{tabular}{|c|c|c|c|c|c|}
\hline & $\begin{array}{l}\text { cTnT } \\
n g / m I\end{array}$ & $\begin{array}{l}\text { MMP-9 } \\
n g / m I\end{array}$ & $\begin{array}{l}\text { Antithrombin III } \\
\text { mg/dl }\end{array}$ & $\begin{array}{l}\text { NGAL } \\
n g / m l\end{array}$ & $\begin{array}{l}\text { IL-8 } \\
\mathrm{pg} / \mathrm{mI}\end{array}$ \\
\hline Controls & 0.01 & 29.25 & 109.50 & 67.00 & 13.82 \\
\hline AMI & 3.20 & 32.35 & 96.00 & 157.00 & 27.30 \\
\hline $\begin{array}{l}\text { Significance } \\
\text { Kruskal-Wallis }\end{array}$ & $P<0.001$ & $P<0.034$ & $P<0.004$ & $P<0.004$ & $P<0.027$ \\
\hline
\end{tabular}

Table 1: Plasma markers detected in healthy subjects (controls) and acute myocardial infarction patients (AMI). Each value represents the median value of eight subjects. The significance $P$ values calculated with Kruskal-Wallis test are reported. activity [15]. In addition it is known that the over-expression of MMP9 causes intravascular thrombus formation in porcine coronary artery [16].

Other authors also described high MMP-9 levels in cardiovascular diseases. MMP-9 was detected in $20 \%$ of the patients reported in the Framingham Heart Study [17]. The presence of this circulating biomarker reflects plaque inflammation, and its plasma concentration indicates the risk of future cardiovascular mortality in patients with CAD [18]. However, none of these studies [17,18] demonstrated that MMP-9 is directly involved in the coagulation process.

The AMI patients had higher NGAL levels (Table 1). NGAL interacts with MMP-9, preserves it from degradation, and modulates its proteolytic activity [19], affecting coagulation [14,15]. It has been reported that NGAL levels are high in patients with CAD [20] and are related to the severity of the disease [8], and are increased in clinical and experimental heart failure [21]. However, although these findings suggest that NGAL may play an active pathophysiological role in the development of coronary events, none of them $[8,20,21]$ demonstrate a direct relationship between NGAL and the priming of coagulation process.

Finally, the AMI patients had high plasma IL-8 levels (Table 1); the same patients show high values of NGAL. It is important to remember that IL-8 exhibits the capacity to recruit the neutrophils [22] that releases NGAL [23], sorted to azurophil granules [24]. In addition, as IL-8 stimulates from human neutrophils [22] the release of NGAL [23] and MMP-9 [25,26] affecting coagulation [14,15], the IL-8 increase, observed, suggest that this factor may facilitate the coagulation process. High values of IL-8 or other chemokines can be used to predict cardiovascular risk [27], and indicate a probable future CAD in normal subjects [28,29]. However, none of these studies [27-29] demonstrate a connection between IL-8 and coagulation.

As IL-8 stimulates from human neutrophils [22] the release of NGAL [23] and MMP-9 [25,26] affecting coagulation [14,15], the observed IL-8 increase suggests that this factor may be involved in facilitating the coagulation process.

\section{Conclusions}

In brief, we detected increased plasma MMP-9 in our AMI patients, who also had high levels of NGAL and IL-8. These markers appear to be interrelated and involved in the process leading to rapid coagulation: a clot starts with MMP-9 priming activity [14], which is modulated by NGAL [19] and affected by IL-8 [25,26]. Although it is also possible that the inflammatory cells found in the morphological changes that occur 12-24 hours after an AMI [1] may contribute to the release of factors affecting coagulation, the origin of the indicators here detected may be also attributed to inflammatory cells infiltrating atherosclerotic plaque $[1-3,14]$.

We suggest that the markers MMP-9, NGAL and IL-8 found in AMI subjects and associated with sudden coagulation may be used in a large-scale study of CAD patients to reveal a risk of acute coronary syndrome.

\section{Acknowledgements}

This study is dedicated to the memory of Professor Cirillo Mussini (17.02.1936 - 17.03.2007), the Founder and first President of the Concorde Group (Spezzano, Modena, Italy).

The authors are grateful to Doctor Luca Mussini, Managing Director to Concorde Group S.p.A. (Spezzano, Modena, Italy) for encouraging and funding this study. 
Citation: Pinelli A, Trivulzio S, Brenna S, Rosato V, Rivoltini L, et al. (2012) Identification of Factors Causing Sudden Coagulation in Patients with Acute Myocardial Infarction. J Clin Exp Cardiolog 3:202. doi:10.4172/2155-9880.1000202

\section{Conflict of Interest}

None of the authors have any conflict of interest in relation to this manuscript.

\section{References}

1. Robbins E Cotran (2010) Pathological Basis of Diseases: Kumar V, Abbas AK Fausto N, Aster JC (Eds). (8 $8^{\text {th }}$ edn), Elsevier Saunders, Philadelphia, USA. 516525, 571-586.

2. Shah PK, Falk E, Badimon JJ, Fernandez-Ortiz A, Mailhac A, et al. (1995) Human monocyte-derived macrophages induce collagen breakdown in fibrous caps of atherosclerotic plaques. Potential role of matrix-degrading metalloproteinases and implications for plaque rupture. Circulation 92: 15651569.

3. Badimon L, Chesebro JH, Badimon JJ (1992) Thrombus formation on ruptured atherosclerotic plaques and rethrombosis on evolving thrombi. Circulation 86 : III74-85.

4. Hemdahl AL, Gabrielsen A, Zhu C, Eriksson P, Hedin U, et al. (2006) Expression of neutrophil gelatinase-associated lipocalin in atherosclerosis and myocardial infarction. Arterioscler Thromb Vasc Biol 26: 136-142.

5. Apostolopoulos J, Davenport P, Tipping PG (1996) Interleukin-8 production by macrophages from atheromatous plaques. Arterioscler Thromb Vasc Biol 16: 1007-1012.

6. Rottbauer W, Greten T, Muller-Bardorff M, Remppis A, Zehelein J, et al. (1996) Troponin $\mathrm{T}$ : a diagnostic marker for myocardial infarction and minor cardiac cell damage. Eur Heart J 17: 3-8.

7. Fu Q, Zhu J, Van Eyk JE (2010) Comparison of multiplex immunoassay platforms. Clin Chem 56: 314-318.

8. Zografos T, Haliassos A, Korovesis S, Giazitzoglou E, Voridis E, et al. (2009) Association of neutrophil gelatinase-associated lipocalin with the severity of coronary artery disease. Am J Cardiol 104: 917-920.

9. Antithrombin: automated chromogenic assay for the quantitative determination of antithrombin in human citrated plasma on the IL coagulation systems. Instrumentation Laboratory, Milan.

10. Ihaka R, Gentleman R (1996) R: a language for data analysis and graphics. J Comput Graph Statist 5: 299-314.

11. R Development Core Team. R: A Language and Environment for Statistical Computing. Vienna, Austria: R Foundation for Statistical Computing. 2010.

12. Moyssakis I, Vlahodimitris IE, Kanakis MA, Kapsimali V, Tsoucala C, et al (2010) Behaviour of coagulation factors and normal inhibitors of coagulation during the acute phase of myocardial infarction. Blood Coagulation \& Fibrinolysis 21: 670-673.

13. Tousoulis D, Antoniades C, Bosinakou E, Kotsopoulou M, Tsoufis C, et al (2007) Differences in inflammatory and thrombotic markers between unstable angina and acute myocardial infarction. Int J Cardiol 115: 203-207.

14. Belaaouaj AA, Li A, Wun TC, Welgus HG, Shapiro SD (2000) Matrix metalloproteinases cleave tissue factor pathway inhibitor. Effects on coagulation. J Biol Chem 275: 27123-27128.
15. Owens AP 3rd, Mackman N (2010) Tissue factor and thrombosis: The clot starts here. Thromb Haemos 104: 432-439.

16. Morishige K, Shimokawa $H$, Matsumoto $Y$, Eto $Y$, Uwatoku T, et al. (2003) Overexpression of matrix metalloproteinase-9 promotes intravascular thrombus formation in porcine coronary arteries in vivo. Cardiovascular Res 57: 572-585.

17. Sundstrom J, Evans JC, Benjamin EJ, Levy D, Larson MG, et al. (2004 Relations of plasma matrix metalloproteinase-9 to clinical cardiovascular risk factors and echocardiographic left ventricular measures: the Framingham Heart Study. Circulation 109: 2850-2856.

18. Blankenberg S, Rupprecht HJ, Poirier O, Bickel C, Smieja M, et al. (2003) Plasma concentrations and genetic variation of matrix metalloproteinase 9 and prognosis of patients with cardiovascular disease. Circulation 107: 1579-1585.

19. Yan L, Borregaard N, Kjeldsen L, Moses MA (2001) The high molecular weight urinary matrix metalloproteinase (MMP) activity is a complex of gelatinase $\mathrm{B}$ / MMP-9 and neutrophil gelatinase-associated lipocalin (NGAL). Modulation of MMP-9 activity by NGAL. J Biol Chem 276: 37258-37265.

20. Sahinarslan A, Kocaman SA, Bas D, Akyel A, Ercin U, et al. (2011) Plasma neutrophil gelatinase-associated lipocalin levels in acute myocardial infarction and stable coronary artery disease. Coron Artery Dis 22: 333-338.

21. Yndestad A, Landro L, Ueland T, Dahl CP, Flo TH, et al. (2009) Increased systemic and myocardial expression of neutrophil gelatinase-associated lipocalin in clinical and experimental heart failure. Eur Heart J 30: 1229-1236.

22. Harada A, Mukaida N, Matsushima K (1996) Interleukin 8 as a novel target for intervention therapy in acute inflammatory diseases. Mol Med Today 2: 482 489.

23. Axelsson L, Bergenfeldt M, Ohlsson K (1995) Studies of the release and turnover of a human neutrophil lipocalin. Scand J Clin Lab Invest 55: 577-588.

24. Le Cabec V, Calafat J, Borregaard N (1997) Sorting of the specific granule protein, NGAL, during granulocytic maturation of HL-60 cells. Blood 89: 2113 2121.

25. Chakrabarti S, Patel KD (2005) Regulation of matrix metalloproteinase- 9 release from IL-8-stimulated human neutrophils. J Leuk Biol 78: 279-288.

26. Van den Steen PE, Proost P, Wuyts A, Van Damme J, Opdenakker G (2000) Neutrophil gelatinase B potentiates interleukin-8 tenfold by aminotermina processing, whereas it degrades CTAP-III, PF-4, and GRO-alpha and leaves RANTES and MCP-2 intact. Blood 96: 2673-2681.

27. Aukrust P, Yndestad A, Smith C, Ueland T, Gullestad L, et al. (2007) Chemokines in cardiovascular risk prediction. Thromb Haemost 97: 748-754.

28. Boekholdt SM, Peters RJ, Hack CE, Day NE, Luben R, et al. (2004) IL-8 plasma concentrations and the risk of future coronary artery disease in apparently healthy men and women: the EPIC-Norfolk prospective population study. Arterioscler Thromb Vasc Biol 24: 1503-1508.

29. Rothenbacher D, Muller-Scholze S, Herder C, Koenig W, Kolb H (2006) Differential expression of chemokines, risk of stable coronary heart disease, and correlation with established cardiovascular risk markers. Arterioscle Thromb Vasc Biol 26: 194-199.

Submit your next manuscript and get advantages of OMICS Group submissions

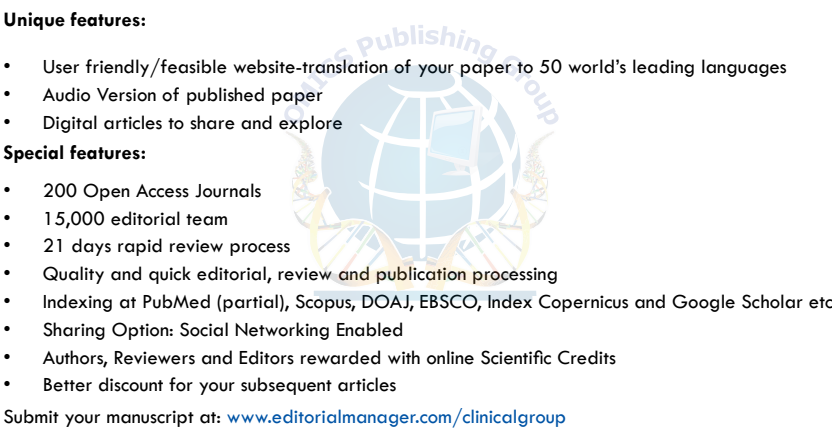

